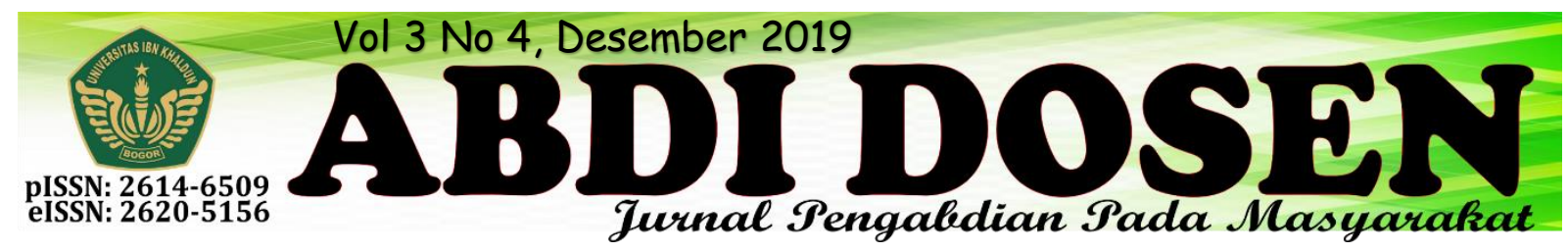

\title{
BERKARYA NYATA MEMBANGUN DESA MENUJU INDONESIA BERKEMAJUAN
}

\author{
Kamalludin $^{1}$, Dini Sufani, Sendi Febriansyah ${ }^{2}$ \\ kamalludin@fai.uika-bogor.ac.id \\ Fakultas Agama Islam Universitas Ibn Khaldun ${ }^{1}$, Mahasiswa KKN Kelompok 34 Tahun $2018^{2}$
}

\begin{abstract}
ABSTRAK
Kuliah Kerja Nyata (KKN) merupakan kegiatan pengabdian kepada masyarakat didaerah tertentu atau lembaga pendidikan, dilaksanakan secara kelompok, teritegrasi antar jurusan, terkoordinasi di tingkat fakultas, diutamakan kegiatan fisik dan nonfisik di segala bidang. Kegiatan KKN bertujuan untuk memberikan pengalaman kerja nyata di lapangan dalam bidang membentuk sikap mandiri dan tanggung jawab dalam pelaksanaan pekerjaan di lapangan. Selain itu, KKN juga bertujuan uintuk membantu masyarakat dalam meningkatkan taraf pengetahuan dan keterampilan sehingga diharapkan dapat meningkatkan kesejahteraannya. Kegiatan KKN dibagi menjadi empat tahap kegiatan, yaiyu pembekalan, pelaksanaan, penyusunan laporan, dan evaluasi. Pelaksanaan KKN ini dimulai dari tanggal 7 Agustus 2018 sampai dengan 5 September 2018 di Desa Situ Udik, Kecamatan Cibungbulang, Kabupaten Bogor. Program kelompok di Desa Situ Udik merupakan program yang lebih menekankan kepada tema pembangunan secara fisik dan non-fisik Masyarakat Desa Situ Udik. Program fisik kelompok 34, antara lain : pembuatan tempat sampah, kerja bakti, pembuatan pamflet peringatan, pembuatan tiang lampu, dan perbaikan sarana prasarana madrasah. Program non-fisik, antara lain : Sosialisasi program KKN, bimbingan belajar, perayaan HUT RI, penyuluhan kesehatan, workshop pendidikan, pengajian bersama, cek kesehatan gratis, sosialisasi menabung, pentuluhan zakat, infaq dan sodaqoh, dan madrasah diniyah.
\end{abstract}

Kata kunci : Berkarya nyata, membangun, dan berkemajuan

\section{PENDAHULUAN}

\section{Analisis Situasi}

Kuliah Kerja Nyata merupakan program pendidikan dengan memberikan pengajaran kepada mahasiswa untuk beradaptasi dengan masyarakat. Ada beberapa tahap diantaranya persiapan, pembekalan, observasi sampai pada tahap evaluasi. Persiapan merupakan kegiatan sebelum KKN dilaksanakan, persiapan dilakukan agar kegiatan dapat terlaksana dengan dengan terstruktur dan terarah. Persiapan dilakukan baik oleh pihak LPPM selaku koordinator dan mahasiswa sebagai peserta KKN. Tujuan dari KKN sendiri adalah mahasiswa diharapkan dapat memberikan bantuan pemikiran, tenaga, dan ilmu pengetahuan dalam merencanakan dan melaksanakan program memajukan desa.

Tujuan kegiatan pembekalan KKN adalah membekali mahasiswa dengan materi pemberdayaan masyarakat melalui KKN dan materi teknis kegiatan kkn. Melalui koordinasi dengan Dosen 
Pembimbing Lapangan (DPL) KKN kelompok secara efektif. Mahasiswa KKN juga mengadakan pertemuan rutin membahas program kerja.

Ketika mahasiswa berada di lokasi KKN, para mahasiswa melakukan kegiatan observasi. Kegiatan ini dilakukan untuk mengamati secara langsung terhadap permasalahan apa yang sedang dihadapi masyarakat dan mahasiswa diharapkan dapat memecahkan permasalahan tersebut. Inilah yang yang disebut Kuliah Kerja Nyata Tematik.

\section{Permasalahan yang Dihadapi}

Kp. Pasar Putih Desa Situ Udik memiliki beberapa permasalahan yang dihadapi oleh masyarakat, di antaranya:

1. Pengelolaan sampah

2. Kurangnya fasilitas lampu jalan

3. Banyaknya masyarakat yang terjerat dengan Bank Keliling.

4. Tidak aktifnya madrasah diniyah

5. Kurangnya guru untuk mengajar

6. Kurang kesadaran masyarakat mengenai pentingnya CTPS (cuci tangan pakai sabun), pentingnya memilih jajanan sehat, dan pentingnya menyikat gigi.

7. Terhambatnya kegiatan posbindu (pos pembinaan terpadu).

8. Kurangnya kesadaran warga untuk melakukan olahraga.

9. Minimnya kualitas pengajar pada tingkat PAUD

\section{Letak Geografis}

Desa Situ Udik merupakan salah satu desa wilayah Kecamatan Cibungbulang Kabupaten Bogor dengan Luas Wilayah 370,150 Hektar yang terbagi dalam 3 dusun, 12 Rukun Warga (RW), 43 Rukun Tetangga (RT), Dengan jumlah penduduk sebanyak 14.071 jiwa yang terdiri dari 6928 laki-laki, 7174 perempuan, dengan jumlah dengan jumlah Kepala Keluarga 3677, sedangkan jumlah keluarga miskin (Gakin) 661 kepala keluarga, dengan presentase 36,67\% dari jumlah keluarga yang ada di Desa Situ Udik. Batas Wilayah Desa Situ Udik adalah sebagai berikut :

Sebelah Utara: Desa Situ Ilir Kecamatan

Cibungbulang

Sebelah Timur: Desa Cimayang

Kecamatan

Pamijahan

Sebelah Selatan: Desa Pasarean

Kecamatan

Pamijahan

Sebelah Barat: Desa Kracak Kecamatan Leuwiliang

\section{Kondisi Masyarakat}

\section{Sosial Ekonomi dan Budaya}

Desa Situ Udik memiliki 3677 kepala keluarga, mayoritas masyarakat Desa Situ Udik sebagai wiraswasta, buruh tani, buruh dan peternak. Terdapat organisasi yang berjalan di Desa Situ Udik yaitu Karang Taruna dan PKK.

Mayoritas agama di Desa Situ Udik menganut Agama Islam. Desa Situ Udik dilengkapi dengan fasilitas ibadah diantaranya satu buah Mushola yang bernama Mushola Nurul Qolbi terletak di RT 02 dan satu buah Masjid yang bernama Nurul Qolbi yang terletak di RT 01. Masyarakat Desa Situ Udik sering mengadakan kerja bakti setiap hari jum'at dan hari minggu, sehingga kerukunan antar warga terjaga dengan baik.

\section{Bidang Pendidikan}

Desa Situ Udik memiliki 5 buah PAUD, 3 buah TK, 2 buah RA, 5 buah TKA/TPA, 2 buah SD Negeri, 4 buah Madrasah Ibtidayah, 3 buah SMP/MTS, 3 Buah SMA, 1 buah PKBM, 1 buah Paket A, 1 buah Paket B, dan 1 buah paket $C$. Untuk Khusus PAUD Nurul Qolbi, Kampung Pasir Putih, dilaksanakan setiap hari kecuali hari minggu dan kamis. Taman 
Pendidikan Al-Qur'an (TPA) dan Kuliah Shubuh, dilaksanakan dari hari senin s/d sabtu, serta remaja masjid.

\section{Bidang Kesehatan}

Pelayanan bidang kesehatan yang ada di Desa Situ Udik yakni Posyandu Nurul Qolbi, diselenggarakan setiap 1 bulan satu kali. Posyando dikelola oleh ibu-ibu PKK. Posyandu ini diperuntukkan untuk balita dan lansia

\section{Bidang Olahraga}

Pada bidang olahraga, Desa Situ Udik memiliki fasilitas untuk olahraga adalah lapangan bola yang berada di RT 02.

\section{METODOLOGI}

\section{Pelaksanaan Program Kerja}

Pelaksanaan KKN Universitas Ibn Khaldun 2018 dimulai pada tanggal 7 Agustus 2018 sampai dengan 5 September 2018 yang pelaksanaannya dilakukan oleh Mahasiswa KKN UIKA dan Masyarakat Desa Situ Udik. Adapun program kerja dirinci sebagai berikut:

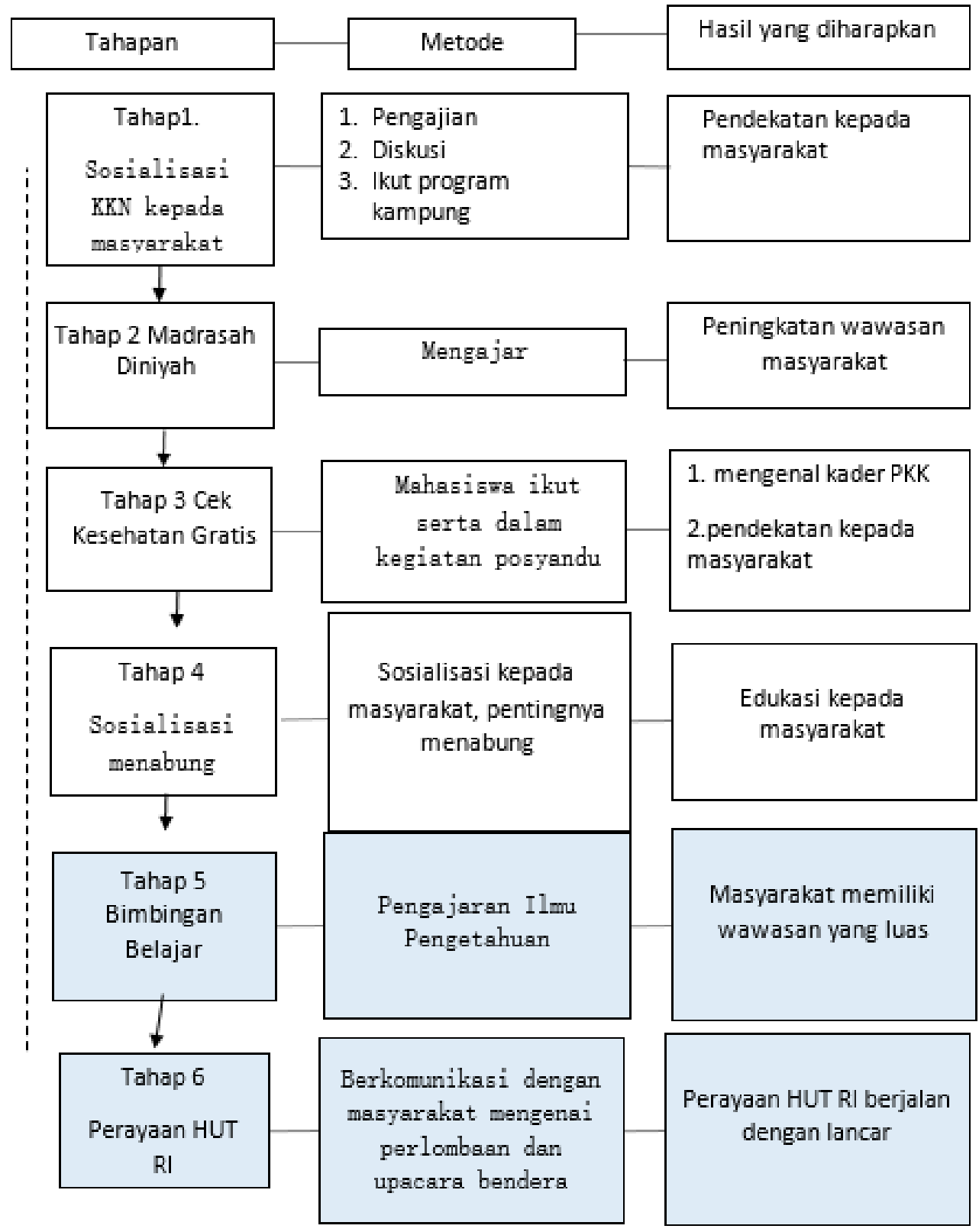




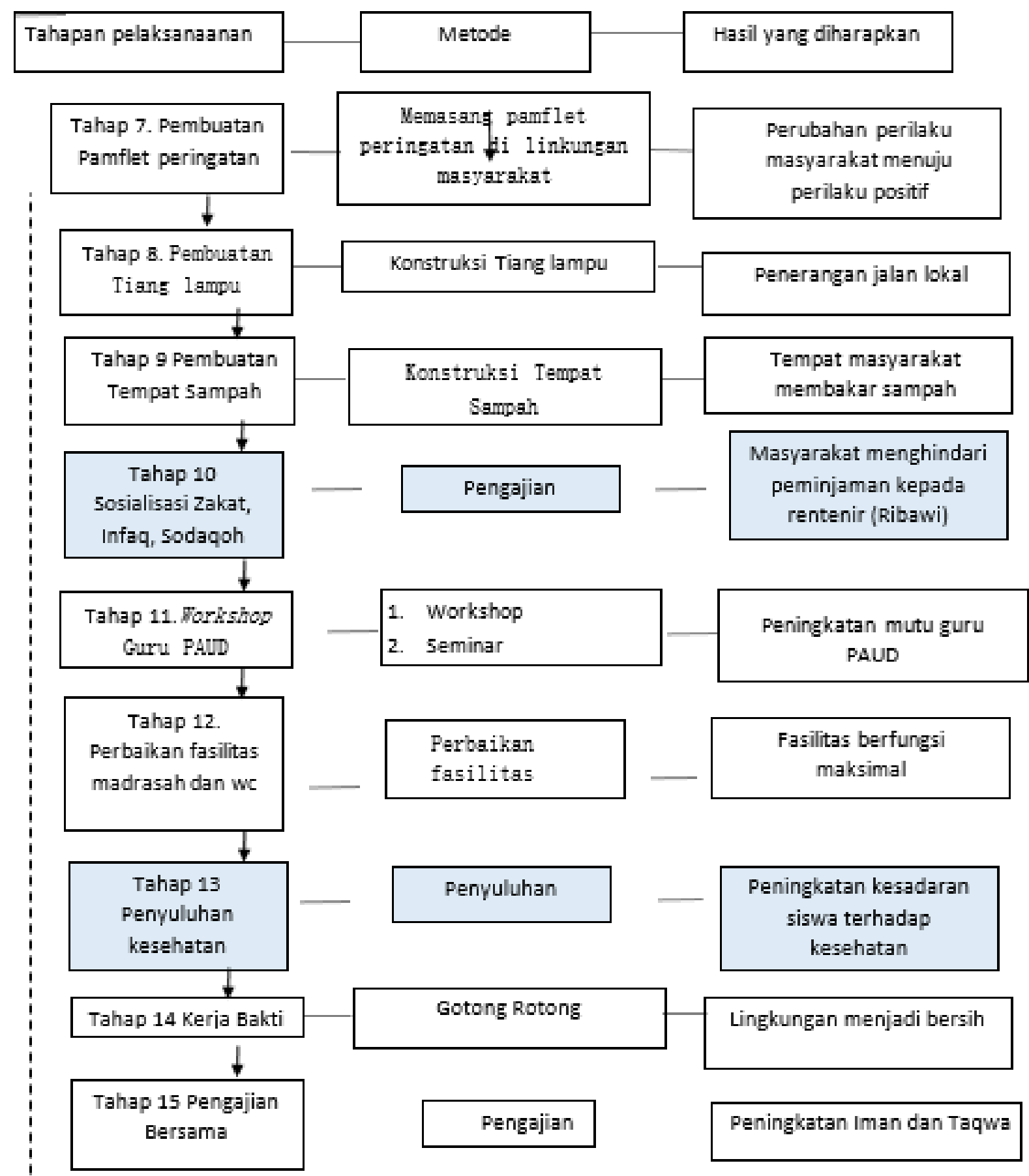




\section{Jadwal Program Kerja}

\begin{tabular}{|c|c|c|c|c|c|c|}
\hline \multirow{3}{*}{ No } & \multirow{3}{*}{ Program Kerja } & \multicolumn{5}{|c|}{ Waktu } \\
\hline & & \multicolumn{4}{|c|}{ Agustus } & \multirow{2}{*}{$\begin{array}{c}\text { September } \\
\text { Minggu } 1\end{array}$} \\
\hline & & Minggu 1 & Minggu 2 & Minggu 3 & Minggu 4 & \\
\hline 1. & $\begin{array}{l}\text { Penyusunan Rencana } \\
\text { Kegiatan }\end{array}$ & 1 & & & & \\
\hline 2 & $\begin{array}{l}\text { Sosialisasi } \\
\text { Rencana Kegiatan }\end{array}$ & & 7 & & & \\
\hline 3 & $\begin{array}{l}\text { Pembuatan Tempat } \\
\text { Sampah }\end{array}$ & & & & 26 & \\
\hline 4 & Bimbingan Belajar & & $13-18$ & $20-25$ & $27-31$ & $1,3 \& 4$ \\
\hline 5 & $\begin{array}{l}\text { Perayaan HUT RI } \\
\text { “17 Agustus” }\end{array}$ & & 17 & & & \\
\hline 6 & Penyuluhan & & 16 & 20 & 29 & \\
\hline 5 & Kerja bakti & & $10 \& 12$ & 19 & $\begin{array}{l}24, \quad 26 \& \\
31\end{array}$ & \\
\hline 7 & Workshop & & & & 25 & \\
\hline 8 & Pengajian bersama & & & & & 2 \\
\hline 9 & Madrasah Diniyah & & $13-16$ & $20-23$ & $27-30$ & \\
\hline 10 & Cek Kesehatan Gratis & & 16 & & 31 & \\
\hline 11 & Pembuatan Tiang & & & & 25 & \\
\hline 12 & $\begin{array}{l}\text { Pembuatan Pamflet } \\
\text { Peringatan }\end{array}$ & & 12 & & & \\
\hline 13 & Sosialisasi Menabung & & 13 & & & \\
\hline 14 & $\begin{array}{l}\text { Penyuluhan Zakat, } \\
\text { Infaq dan Sodaqoh }\end{array}$ & & 18 & & & \\
\hline 15 & $\begin{array}{l}\text { Perbaikan Sarana dan } \\
\text { Prasarana Madrasah }\end{array}$ & & & & 26 & \\
\hline 16 & $\begin{array}{l}\text { Monitoring dan } \\
\text { Evaluasi }\end{array}$ & & $8-13$ & $14-21$ & $22-31$ & $1-2$ \\
\hline 17 & Penyusunan Laporan & & & & $27-31$ & 1 \\
\hline
\end{tabular}




\section{Metode pendekatan}

Pendekatan yang digunakan dalam kegiatan ini adalah:

1. Pendekatan Religius yaitu pendekatan yang menggunakan nilai-nilai agama sebagai basis kegiatan. Pendekatan ini sangat penting karena sangat dipengaruhi oleh faktor keimanan, pengalaman keagamaan, rasa tanggung jawab dan pengetahuan. Pendekatan Religius yang kami lakukan melalui berpartisipasi dalam pengajian ibu-ibu, pengajian bapak-bapak, pengajian pemuda dan pengajian anak-anak.

2. Pendekatan organisasi, yaitu pendekatan dimana seluruh kegiatan di organisir

\section{PEMBAHASAN DAN HASIL}

\section{Perumusan Program Kegiatan}

Kuliah Kerja Nyata (KKN) yang dilaksanakan pada tanggal 7 Agustus 2018 sampai 5 September 2018, sebelumnya telah melalui serangkaian persiapan untuk mendukung terlaksananya program kerja KKN. Persiapan telah dilakukan baik oleh pihak LPPM selaku koordinator dan mahasiswa sebagai peserta KKN. Serangkaian persiapan antara lain : melakukan observasi ke desa tempat praktik lapangan yang dilakukan sebanyak satu kali, yaitu pada tanggal 31 Juli 2018 atau 1 Agustus 2018 yang meliputi observasi fisik dan nonfisik desa.

Pembekalan KKN yang dilakukan oleh pihak LPPM dengan materi pemberdayaan masyarakat melalui $\mathrm{KKN}$, materi Training of Trainer (TOT) terkait dengan teknis kegiatan $\mathrm{KKN}$ pada tanggal 30 Juli Agustus 2018. Melakukan koordinasi dengan Dosen Pembimbing Lapangan (DPL) KKN kelompok secara efektif. Mahasiswa KKN juga melakukan koordinasi, rapat, dan pertemuan kelompok untuk membahas program kerja. oleh PAUD Nurul Qalbi dan organisasi pemuda.

3. Pendekatan kekerabatan, artinya bahwa pembinaan yang dilakukan senantiasa dikaitkan dalam rangka membangun kekerabatan antar masyarakat yang semakin memudar. Pendekatan kekerabatan biasanya kami lakukan melalui bersosialisasi dengan masyarakat, bermain setiap sore bersama anak-anak, mengunjungi rumah warga dan mengadakan acara makan-makan dengan masyarakat agar hubungan kekerabatan tetap terjaga.

Melakukan koordiansi dengan pihak masyarakat dan perusahaan yang berkaitan dengan pelaksanaan kegiatan KKN.

Setelah melaksanakan pendataan dan observasi desa, baik dari segi fisik maupun nonfisik, selanjutnya merumuskan prograprogram kerja yang sesuai, melakukan koordinasi dan tindak lanjut pada Dosen Pembimbing Lapangan (DPL), Kepala Desa Situ Udik dan pihak masyarakat yang berkaitan dengan pelaksanaan kegiatan KKN. Program-program yang ada meliputi program kelompok. Program-program terdiri program fisik, program non-fisik. Program kelompok diklasifikasikan atas tiga macam yaitu (1) program utama dan (2) program penunjang. Program kelompok adalah program yang direncakana, dilaksanakan, dan dipertanggungjawabkan oleh seluruh anggota kelompok meskipun pada teknik pelaksanaanya. Program ini dikerjakan oleh minimal lebih setengah jumlah anggota kelompok. Program utama adalah program yang diangkat berdasarkan kompetensi bidang studi atau keahlian khusu yang dimiliki oleh mahasiswa 
peserta KKN, sedangkan program yang diluar itu disebut program penunjang.

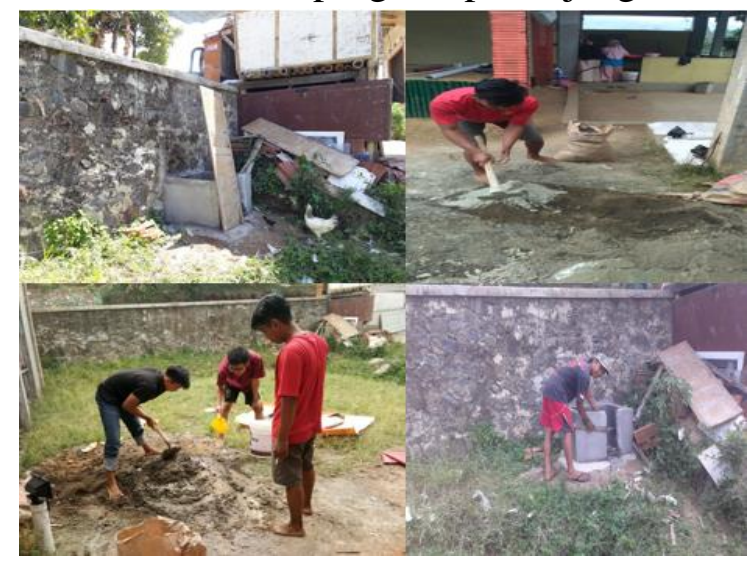

\section{Pembuatan tempat sampah}

Kegiatan pembuatan tempat sampah dilakukan untuk menyediakan tempat untuk pembakaran sampah masyarakat Desa Situ Udik.

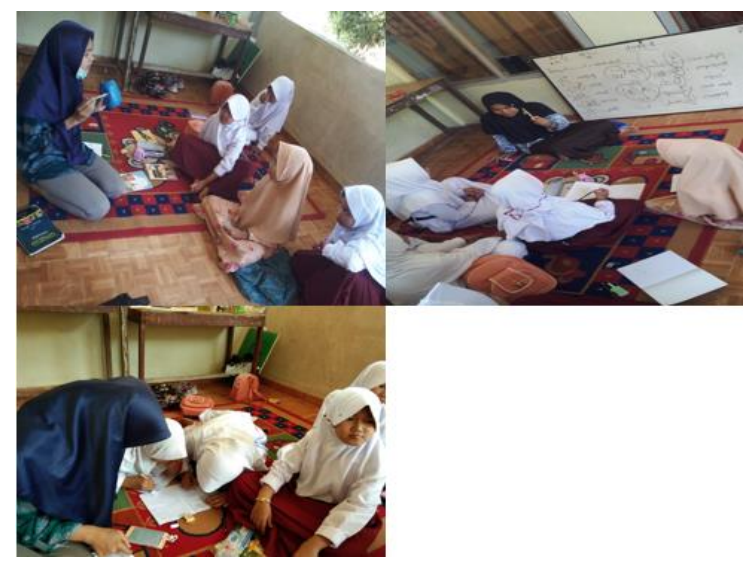

\section{Bimbingan belajar}

Merupakan kegiatan belajar mengajar yang bertujuan untuk memudahkan para siswa yang kesulitan belajar dan mengerjakan tugas sekolah, dengan cara yang tidak jenuh, bermain tetapi sambil belajar, agar para siswa menikmati belajarnya.

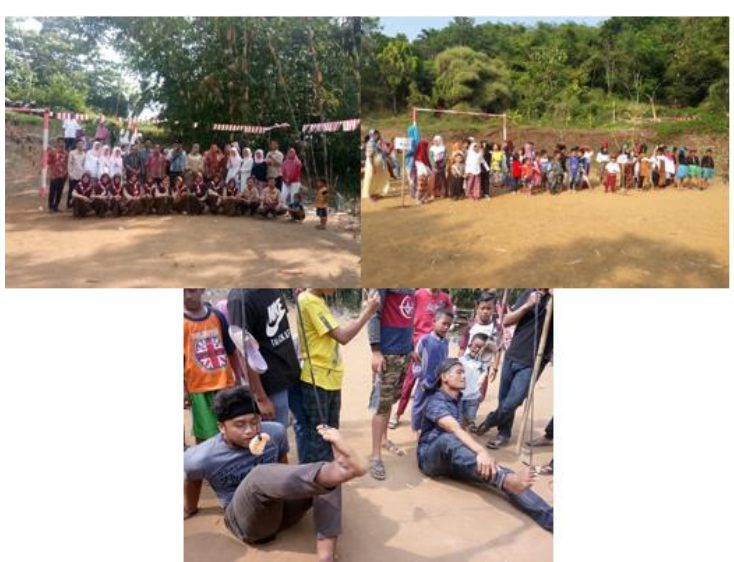

\section{Perayaan HUT RI}

Merupakan kegiatan nasional yang diadakan pada tanggal 17 Agustus 1945, dengan tujuan mengenang para pahlawan yang membela tanah air, sehingga 17 Agustus diperingati sebagai Hari Kemerdekaan Indonesia. Dengan cara, Upacara Bendera Merah Putih dan perlombaan anak-anak.

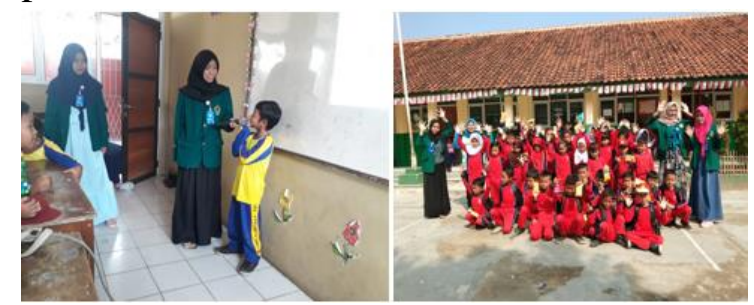

\section{Penyuluhan kesehatan}

Penyuluhan Kesehatan berupa materi Pola Hidup Sehat (PHBS) bertujuan untuk mengajak anak kecil dan remaja di Desa Situ Udik untuk hidup sehat. Mengingat jumlah anak kecil dan remaja yang sangat banyak, sebesar 2134 jiwa umur 0-4 tahun, 1491 jiwa umur 5-9 tahun, 1559 jiwa umur 10-14 tahun dan 1432 jiwa umur 15-19 tahun.

\section{Kerja bakti}

Merupakan program kerja yang bertujuan untuk membersihkan lingkungan Desa Situ Udik, agar lingkungan bebas dari berbagai macam penyakit.

\section{Workshop pendidikan}

Tujuan dari program ini adalah meningkatkan mutu para guru, khususnya guru PAUD Desa Situ Udik. 


\section{Pengajian bersama}

Tujuan dari kegiatan ini adalah sebagai penutupan kegiatan mahasiswa KKN yang diselimuti dengan pengajian dalam rangka peningkatan Iman dan Taqwa.

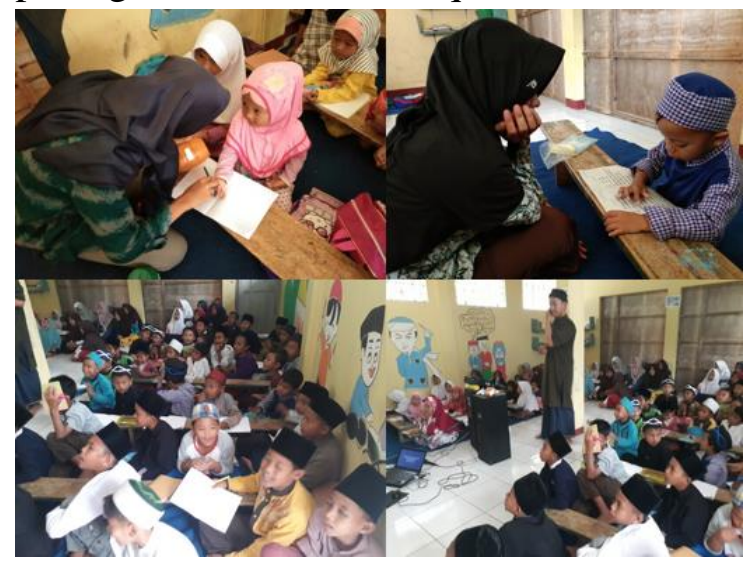

\section{Madrasah diniyah}

Merupakan sebuah kegiatan keagamaan yang berupaya untuk mendidik mengenai wawasan Islam. Tujuannya, agar siswa yang belajar di sekolah negeri mendapatkan asupan ajaran agama yang cukup dari Madrasah Diniyah. Karena Madrasah Diniyah Nurul Qolbi, sudah tidak berjalan 2 tahun yang lalu, karena kendala waktu dan kekurangan staff pengajar. Oleh karena itu, penulis berinisiatif untuk menghidupkan kembali madrasah tersebut.

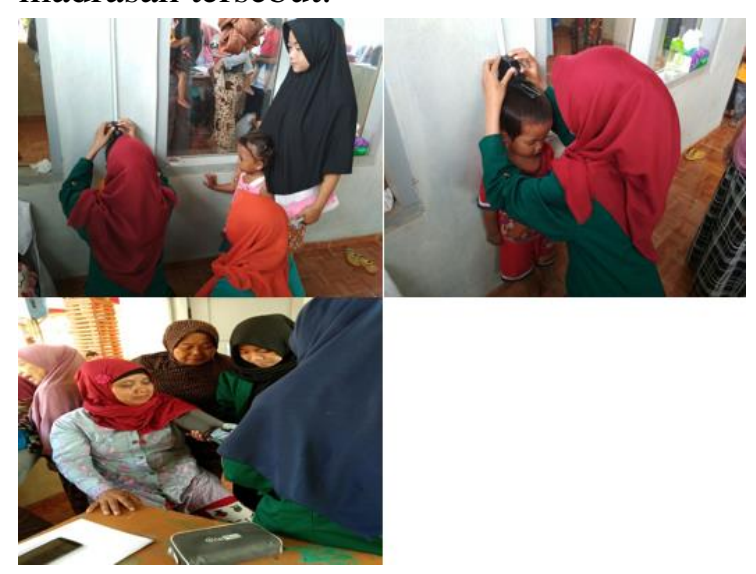

\section{Cek kesehatan gratis}

Tujuan dari Cek Kesehatan Gratis adalah mempermudah Masyarakat Desa Situ Udik dalam rangka pengecekan kesehatan dan peningkatan mutu kesehatan Masyarakat Situ Udik.

\section{Pembuatan tiang lampu}

Kegiatan ini dilakukan dalam rangka untuk menerangi jalan yang gelap, karena jalan lokal Desa Situ Udik gelap dan rawan pencurian.

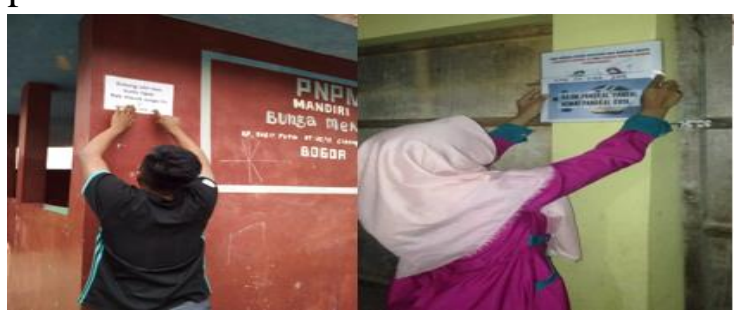

\section{Pembuatan pamflet larangan}

Kegiatan ini bertujuan untuk mengingatkan kepada masyarakat untuk selalu berprilaku positif. Contohnya: Pamflet tidak buang sampah sembarangan, selalu semangat dalam menuntut ilmu, dsb.

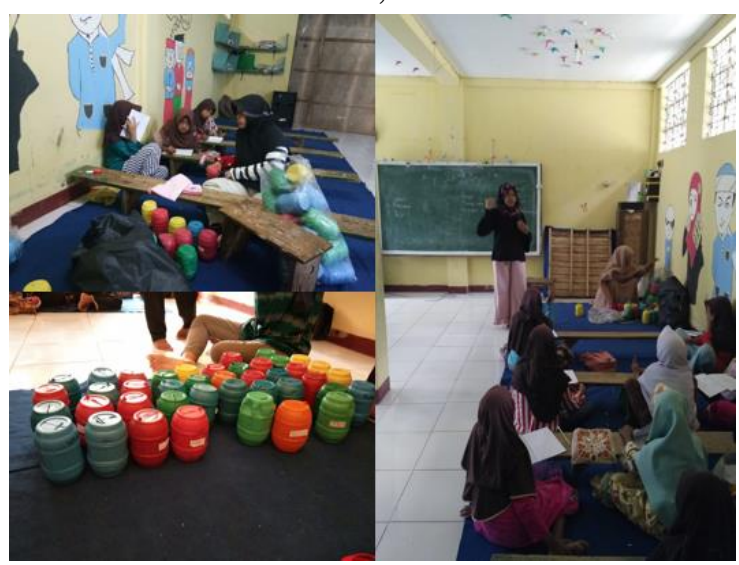

\section{Sosialisasi menabung}

Kegiatan ini bertujuan untuk membiasakan menabung untuk anak-anak dan remaja di daerah Desa Situ Udik. Karena menabung itu amat penting sekali untuk masa depan yang akan datang.

\section{Penyuluhan zakat, infaq \& sodaqah}

Kegiatan ini bertujuan menyadarkan masyarakat untuk menghindari peminjaman kepada bank keliling atau rentenir. Denga kata lain, islam memiliki solusi yang terbaik, dibandingkan dengan peminjaman kepada rentenir. 


\section{Perbaikan Sarana dan Prasarana Madrasah}

Kegiatan ini menjaga dan merawat Madrasah Nurul Qolbi, sebagai berikut : peremajaan pintu dan engsel madrasah .

\section{KESIMPULAN}

Kegiatan KKN dengan sasaran Masyarakat Desa Situ Udik secara umum berjalan dengan lancar sesuai apa yang direncanakan, meski target waktu yang direncanakan tidak dapat sepenuhnya dijalankan sesuai dengan hal tersebut, namun hal tersebut tidak merubah esensi pelaksanaan program tersebut. Adapun kesimpulan dari pelaksanaan program kerja KKN masyarakat yaitu :

1. Program KKN dapat terlaksana dengan baik dan lancar meski ada beberapa

\section{SARAN}

Berdasarkan hasil pelaksanaan program KKN yang dilaksanakan sejak 7 Agustus 2018 sampai 5 September 2018, terdapat saran yang sekiranya membangun bagi semua pihak, seperti masyarakat Desa Situ Udik. Saran kepada Masyarakat Desa

\section{DAFTAR PUSTAKA}

Mujahidin. (2017). Program Pengabdian Kepada Masyarakat. Bogor: UIKA.

Rosyadi, R., \& Prasetya, E. P. (2018). Petunjuk Pelaksanaan KKN Tematik Terintegrasi 2018. Bogor: UIKA Press. perubahan dan tambahan serta waktu pelaksanaan yang kurang sesuai dengan yang direncanakan.

2. Program Kerja KKN dapat berjalan dengan baik berkat Ridho Allah, dengan perantara, dukungan dan kerja sama antar warga yang sangat membantu.

Dengan demikian, hasil kesimpulan diatas menunjukkan bahwa secara garis besar program KKN dapat dikatakan sukses dan lancar, meskipun waktunya lebih maju atau lebih mundur

Situ Udik ialah program-program yang telah dilaksanakan oleh mahasiswa dan masyarakat, sebaiknya ada pengembangan ataupun tindak lanjut untuk peningkatan selanjutnya.

Setianingsih, A., Fitriyanto, A., Nugroho, A., Fathianhayati, A., Lalilatulrohmah, D. K., \& Azizah, L. (2015). Laporan Kelompok Kuliah Kerja Nyata (KKN) UNY Kelompok 2041. Yogyakarta: Kelompok 2041. 